Paper presented at the conference on "Liberal Education in a Knowledge

Society," La Salle, Illinois, May 30 - June 1, 1997

Bereiter, C. (in press). Education in a knowledge society. In B. Smith (Ed.), Liberal education in a knowledge society. Chicago: Open Court.

\title{
Education in a Knowledge Society
}

\section{Carl Bereiter}

Two of the most important influences on educational planning today are what for want of an established name I will call the futuristic business literature and the work coming out of cognitive science, broadly defined. There are, of course, many other influences, often from groups with a concern for some particular subject or aspect of schooling. But the two I have named are especially sweeping in their implications for educational change, each, in quite different ways, suggesting a reconceptualization of what schooling should be about. Yet each of these stops short of answering the question, "What should it mean to be an educated person in the 21st century?"

That is the kind of question that has motivated the development of liberal education and its periodic transformations. The rise of the natural sciences led to the most profound transformation of liberal education. There were fears that it might not survive the transformation but it did, and no one would any longer conceive of an educated person who was ignorant of science. Now we are facing the possibility of a more radical transformation, one that does not involve so much the incorporation of new disciplines as a change in the way all disciplines are approached. Rumblings of such a transformation have been occurring throughout the past century, but the two new influences, along with the technologies they draw upon, may finally make it happen. Will it mean the end of liberal education (assuming it is not already dead) or will liberal education reemerge, strengthened through its renovation? I think liberal education can be renewed, but it will take a careful synthesis of new ideas and enduring principles.

Liberal education is essentially enculturation. It is more than the handing on of a body of knowledge and wisdom, although that is a large part of it. That is the part that liberal education has in common with enculturation in all societies. What makes liberal education distinctive-what makes it 'liberal' —is its cosmopolitanism. Liberal education initiates the young into a culture that 
transcends the particularities of their social and ethnic backgrounds. A major concern of many advocates of liberal education is that cosmopolitanism itself is coming under attack. Although I share that concern, I shall not dwell on it here. It has been more than adequately discussed. Instead, I will assume in the ensuing discussion that cosmopolitanism of some kind is an agreed-upon end of education. The liberal tradition, the new wave of economic globalization, and recent advances in the learning sciences all point in this direction. But how is such cosmopolitanism to be achieved when cultures are colliding and undergoing rapid, perhaps catastrophic change, when knowledge is expanding more rapidly than anyone can keep up with, and when the process of enculturation itself is subject to radical innovation? That is the question I raise for discussion here.

The discussion begins by drawing out the contrasting educational implications of the futuristic business literature and of cognitive learning research-the one emphasizing skills and personal qualities, the other emphasizing knowledge. Merging the two into lists of educational objectives, as is now common, does not begin to resolve underlying differences. The resolution I propose depends upon taking seriously the idea of a knowledge society, a society organized around the production of knowledge in the same sense that an agrarian society is organized around agricultural production and an industrial society is organized around manufacture. My proposal is that the school should be a productive part of that society, a workshop for the generation of knowledge. Transforming schools into workshops for the production of knowledge mobilizes those skills and personal qualities valued by business futurists, putting them to work toward ends that are consistent with contemporary conceptions of learning and with the objectives of a modernized liberal education.

Two Views of Education for the 21st Century

By the 'futuristic business literature' I refer to that flood of publications from organizational theorists, management consultants, economists, futurologists, and diverse social scientists that take as a backdrop the rapid rate of technological change, the rise of Asia Pacific economies, digitization, globalization, outsourcing, the shift from a manufacturing-based to a knowledge-based economy, and the need for constant innovation. This literature covers a great range in quality of ideas, which raises the twin dangers that policy makers may be influenced most by the lowest level and easiest to grasp ideas and that 
discriminating people will reject the whole literature, thereby ignoring ideas that provide a basis for well-reasoned new educational policies.

Some low-end educational ideas are that technology will revolutionize everything, that we don't need schools anymore, and that there is no use mastering any body of knowledge because it will soon be obsolete. The high-end educational ideas mainly flow from a recognition of the ascendant importance of knowledge: knowledge as a third factor in production, along with capital and labor; learning as the means for organizations to gain a competitive edge; finally, the idea of a social transformation going on that is as extreme as the 19thcentury shift from an agrarian to an industrial society-the shift to a knowledge society.

When it comes to formulating curriculum guidelines, however, the low-end and the high-end ideas seem to point in the same direction. They point to a set of personal qualities that must be cultivated if the education system is to produce people who can thrive in and contribute to the new order: imagination and creativity, ability to work in groups, communication skills, information-finding skills, problem solving abilities, technological literacy, and above all a continual readiness to learn. It is difficult to fault these, and they are now appearing conspicuously in curriculum guidelines and standards. But are they sufficient, and do they point educational planning in the right direction? That they are not the only answer becomes evident if we consider these questions from the perspective of cognitive learning research.

Because the term 'cognitive learning research' is sometimes seriously misinterpreted, I need to make a brief digression. When I was little my mother used to listen to a soap opera in which the commercials repeatedly extolled the gentle virtues of Ivory Snow in contrast to "harsh granulated soap." As an impressionable child I accordingly developed an intense dislike for that uglysounding substance. It therefore came as a shock when I learned later that Ivory Snow was also granulated soap. (Granulated simply means that the soap comes in particles rather than as a cake.) The only discriminative force was in the word "harsh." Cognitive science seems to be attracting the same undeserved scorn as granulated soap. Every new theory that makes a place for emotion, embodiment, sociality, or culture is contrasted with "conventional cognitive science" or "cognitive science based on the computer metaphor," and so many educators and social scientists have got the idea that cognitive science is some 
ugly, sterile, mechanistic undertaking intent on reducing minds to computer programs. But those new theories are granulated soap too.

Cognitive science embraces an increasing range of approaches, addressing an increasing range of issues. It gains its strength from disciplined pursuit of the question, "How does it work?" Cognitive learning research shares this wideopen character. There is no established 'cognitive approach' in education. Yet, for all its diversity, when the work of cognitive educational researchers is put alongside the futuristic business literature, the kinds of prescriptions for education in the 21st century suggested by these two bodies of work are seen to differ profoundly. The emphasis of the business literature is on process outcomes, on turning out students who function in such-and-such ways. The current emphasis in cognitive learning research is on content, on turning out students with a genuine understanding of science, mathematics, and other school subjects.

Educational reformers inspired by the futuristic business literature commonly minimize the value of content mastery. For instance, an announcement of Stanford University's "Just-In-Time Learning on Internet" project confidently proclaims, "Traditional text books and traditional teaching methods requiring weeks of study are being made obsolete by the information explosion." The project leaders suggest that publishers might abandon their traditional bookish ways and start charging customers on a "pay-per-question" basis (White \& Korner, 1995).

Are cognitive learning researchers, then, simply out of touch with the digital age? On the contrary, it seems that most of the business writers-along with many educators, unfortunately-are out of touch with progress in the understanding of learning. In the 1970s, cognitive learning research was where the futuristic literature is now, emphasizing cognitive strategies and learning-tolearn. For a combination of reasons, the emphasis has since shifted dramatically toward content learning. First there was the research on reading, which demonstrated that the overriding determinant of what one will get out of reading is what one already knows about the topic (Anderson \& Pearson, 1984). Then there was the accumulation of research on expertise, which showed that in all kinds of areas, practical as well as intellectual, expertise depends more on deep knowledge of one's domain, its problems and tools, than it does on general mental abilities (Chi \& Glaser, 1988). Perhaps most surprising was the research on misconceptions, which added up to the conclusion that students are passing 
through the schools having failed to grasp most of the ideas that constitute modern knowledge. Schools, it appears, are turning out graduates with preNewtonian conceptions of physics, preDarwinian conceptions of biology, and preSmithian conceptions of economics (Wandersee, Mintzes, \& Novak, 1994) This ought at least to give some pause to futurists who imagine students at home in a postmodern world of quanta and dynamic systems. ${ }^{1}$ Finally, however, the emphasis on content has been buoyed by the successes of new educational efforts aimed at learning with understanding. Once students start to get deeply into the pursuit of understanding, they begin to show spontaneously all the traits that the futuristic business literature urges: imagination, collaboration, problemsolving, communicative skill, and readiness to go on learning.

A commonsense response to the differing implications of futuristic business literature and cognitive learning research would be, "Let's have both." Why not teach both the general skills and dispositions urged by the former and the deep content knowledge stressed by the latter? In fact, that is what curriculum guidelines and standards are tending increasingly to propose (cf. New Standards, 1995). Attractive as this eclectic solution may be, its effect is to drain away the energy that might have produced something new and exciting out of the interaction of these two new forces.

\section{A New Culture for Learning}

The futuristic business literature does convey a revolutionary vision, but it is not to be found in the paragraphs on education. Those are, for the most part, a mixture of technological euphoria and run-of-the-mill school-bashing. The revolutionary vision has to do with knowledge-based organizations-ones whose competitive advantage depends on cultivation and use of the organization's knowledge resources. Because those knowledge resources are generated out of (and to a large extent reside in) the work of everyone in the organization, maximizing them requires designing the organization so as to make everyone a contributor. That is the revolutionary part: abandoning bureaucratic structures in which a worker's responsibility is defined by routine

\footnotetext{
${ }^{1}$ Any notion that students should be able to leap directly from premodern to postmodern understanding of the natural world ought to be abandoned. The misconceptions research indicates that students' failure to grasp key notions such as acceleration, natural selection, and market reflects a failure to grasp the relatively simple systemic relations that constitute a Newtonian or Darwinian or Smithian theory. That students might be able to grasp the more complex systemic relations that constitute contemporary theories seems therefore a mere pipe dream.
} 
tasks and where nonroutine problems are referred to a higher level, replacing them by mission-oriented team structures in which problems are solved and new knowledge is generated within the working groups. That vision has much in common with a new vision of education taking shape within cognitive learning research. The two together, I believe, joined with the enduring vision of a liberal education, do give us an idea of what education for the 21st century should be.

Early cognitive learning research was not only focused on cognitive strategies, it was also focused on the individual learner. Along with a shift toward content came a shift from trying to inculcate learning strategies in the individual student to trying to create classroom cultures that support inquiry and the pursuit of deeper understanding. Educational historians will probably give credit for this shift to a revival of Vygotsky's socio-cultural theory of development and to the theory of situated cognition, which came out of anthropology. These ideas found a ready audience, however, among cognitive learning researchers who had spent the previous decade trying to improve learning by teaching individual cognitive strategies. It was not that the strategies did not work or that they were too hard to teach. The results were often quite impressive in the short run. You could get children to think harder and better about what they were reading and writing and about the problems they were trying to solve, but the effects tended to dissipate as they went on with regular classroom life. We seemed to be teaching a level of mental activity beyond anything required in normal schooling.

It became evident, therefore, that any general upgrading of students' intellectual abilities and dispositions would require changing the prevailing culture of the classroom. Ordinary classroom life is organized around activities (Doyle, 1986). This is true across the whole spectrum ranging from tightly controlled classrooms where the main activity is filling in workbook pages to child-centered classrooms where the activities are self-chosen and often selfinitiated projects. The new challenge has become to reorganize classroom life around the pursuit of knowledge.

The shift from focus on individual cognitive strategies to classroom culture is clearly delineated in the influential work of Ann Brown. In the 1970s her research dealt with teaching memory strategies to mildly retarded children (Brown, 1978). By the 1980s individual strategy instruction had evolved into 'reciprocal teaching' (Palincsar \& Brown, 1984), in which children were organized into what might be 
characterized as rather highly structured support groups for reading comprehension. Reciprocal teaching then became assimilated into the more comprehensive 'communities of learners' (Brown \& Campione, 1990) in which the students became researchers and teachers of one another. Similar if not so clearly demarcated shifts occurred among many of the other cognitive learning researchers who had started out working with individual cognitive strategies.

The cultural shift that is implied in the new cognitive approaches remains poorly understood in the educational community, however-the shift, that is, from classroom life organized around activities to classroom life organized around the pursuit of knowledge. Instead, reciprocal teaching, communities of learners, and other transformations of classroom culture are merely perceived as new activities to replace or supplement old ones. The hottest innovations going in schooling today are 'project-based learning' and 'multiple intelligences.' The first is an old idea from the progressive education era brought back to life by new electronic media. The second is based on a theory of intelligence (Gardner, 1983) that has stimulated the invention of all kinds of new activities. New and more educative activities may indeed improve learning, but they short-circuit efforts to bring about the cultural shift that seems essential if schools are to play the role in knowledge development that cognitive research indicates they should.

In order to take hold, I believe, this cultural shift must assume a more revolutionary form. Otherwise it will be continually reduced to "hands-on learning," "learner-centered education," or some other refurbishment of progressive education. Here is where the ideas about organizational transformation and knowledge work, prominent in the business literature, may be of service. ${ }^{2}$ What I shall propose is that schools be reconstituted along the lines of other organizations whose function is to produce knowledge.

Learning goes on in all organizations, but only some organizations have the function of producing knowledge. The learning that goes on in any organization, whether it is a shoe factory or a research laboratory, is internal to individual minds and to the developing practices of work groups and of the organization as a whole. The excitement over the idea of a 'learning organization' reflects a

\footnotetext{
${ }^{2}$ The business literature is having some influence at the level of school administration. There are school systems endeavoring to adopt Total Quality Management, for instance. (See the special issue of Educational Leadership, November, 1992, devoted to TQM.) But that is on an entirely different plane from the classroom-level transformation I am talking about.
} 
growing appreciation of the value of this learning. It increases the competence of the organization to perform its functions; in these intensely competitive times, learning is one way for an organization to gain a competitive edge. Accordingly, we see efforts to promote learning that range from formal courses in companyrun schools to coffee bars where employees may hang out and exchange instructive stories about their work (Wenger, 1995).

In addition, however, and quite apart from this internal betterment that we call learning, some organizations have the job of producing knowledge. These include university research centers, independent laboratories, market research and opinion research companies, and research and design departments within larger organizations. Unfortunately, in the current learning organization lingo, this knowledge production is called learning, too, thus obscuring an important distinction. ${ }^{3}$ Of course, learning goes on in these knowledge-producing organizations as in all others-learning that develops the competence of the organization to do its work. But the work of the organization is not learning, it is producing knowledge. We accordingly refer to these as knowledge building organizations (Bereiter \& Scardamalia, 1996; Scardamalia \& Bereiter, in press; Scardamalia, Bereiter, \& Lamon, 1994). A research laboratory is a knowledgebuilding organization. A shoe factory is not, although it may contain a research group that is. ${ }^{4}$ Schools today are not knowledge building organizations. I am proposing that they become so. That is a radical cultural shift.

The school becomes a workshop for the production of knowledge. The students are workers. They are learners, too, of course; and because of the nature of their work they may be expected to learn a great deal. But learning is not their job. Their job is producing knowledge. It is meaningful work, because what they are producing is something for their own use, and so their work has that quality, so rare in the industrial age, that comes with building one's own house or raising one's own food.

Many educators would endorse this proposal in the belief that it is what they are already doing. Yet very little of so-called 'constructivist' pedagogy that I have

\footnotetext{
${ }^{3}$ Senge (1996), evidently sensing that a distinction is needed, has introduced a contrast between 'adaptive learning' and 'generative learning,' the latter being learning that creates novelty. This is a help, but things become even clearer if we recognize that knowledge creation is not learning at all, even though-like all intentional activity-it results in learning for those engaged in it.

${ }^{4}$ I have read, however, that Nike does not actually manufacture shoes. They design shoes and contract out their manufacture. Thus, it would appear, Nike is in fact in the knowledgeproducing business, with its knowledge being translated by others into physical objects.
} 
observed or read about is actually concerned with the production of knowledge. Instead, it is concerned with the carrying out of projects that use knowledge but have some other objective than its production. Students may plan a trip to Mars or the building of a station on the moon, they may draw up an environmental or a business plan, or they may play a game or even create a game. At their best, such projects may generate a considerable amount of learning, but it is important to realize the difference between them and authentic knowledge creation.

This difference is dramatized in an experiment by Yarnall and Kafai (1996). I will dwell on this experiment because, by providing a sharp contrast, it serves to clarify what is meant by engaging students in the production of knowledge as distinct from engaging them in knowledge-related projects. Yarnall and Kafai adopted an approach called "Learning Science Through Design." In the course of studying ocean habitats, elementary school students were set to work creating educational computer games related to the ocean theme. In their report, Yarnall and Kafai lump this approach together with Community of Learners (Brown \& Campione, 1994) and CSILE (Scardamalia \& Bereiter, 1994) as 'project-based' approaches. While that is an accurate categorization, it reflects the common weakness in elementary education for elevating a procedural characteristic to the status of a pedagogical philosophy. The authors then proceed to distinguish Learning Science Through Design from the other two approaches in that it is less structured and awards students a higher level of "creative control over the production of an artifact."

Evidently the students did throw themselves energetically into creating the computer games; they collaborated, consulted experts, and discussed programming problems. So if the purpose was to teach software design and programming, the project would have to be considered a success. But what about "Learning Science Through Design"? In 20 out of the 20 games the task the designers set for players was to answer quiz-type questions. Some of the games were explicitly modeled on quiz shows. Most, it appears, used the ocean theme as context for the quiz questions (if you don't answer the question correctly a grouper bites you, for instance). A computer bulletin board was used for discussion, but, the authors report, the discussions were about game design and programming, not about oceans. Incredibly, the one science question posted was rejected by the teacher, who told the student not to expect others to do his research for him! The authors are candid in concluding that "Learning Science 
Through Design"in this instance failed "to create a consistent context for a deeper level of subject inquiry," and they suggest that in the future their method might need "to structure the electronic exchanges around content more along the lines described by both Scardamalia and her colleagues in the CSILE project and Brown and her colleagues in the COL environment." This sounds like a minor modification in procedure, however, whereas doing so successfully-that is, getting students truly engaged with problems of marine biology instead of being solely concerned with software design-would involve a shift in focus so radical that the game-building activity might no longer be relevant.

I have seen students in a Community of Learners classroom intensely engaged with the problem of how male sea otters are able to mark off a territory of ocean as their own-a problem that was not handed to them but that they hit upon themselves as an anomaly in information they had assembled. The same sort of thing occurred in a CSILE classroom when a group studying the Arctic biome could not reconcile the reasons they were given for why trees do not grow in the Arctic with information other groups were providing about trees growing in deserts and in tropical rainforests.

The issue here is not only the learning of science content. It is also learning about knowledge: learning that it is more than stuff sitting in textbooks to be used for answering quiz questions. Even more, it is a matter of gaining experience of what I take to be the essence of life in a knowledge building organization: the experience of producing knowledge of real value to someone.

This is not to rule out games, imaginary trips to Mars, and other often cleverly designed activities occupying that category now fittingly named 'edutainment.' But the extreme prominence given to them in modern pedagogy suggests to me an underlying belief that students have to be lured into learning, that they cannot be expected to pursue knowledge in its own right. No one says this openly, however, for belief in children's natural curiosity as the driving force in learning is one of the pillars of child-centered education. What I do hear, however, is something even less savory. When I show educators examples of students' genuine, sustained efforts to construct real knowledge, someone almost always remarks, "That's fine for students who are motivated, but what about..." and there follows one of those shrugs or evasive mumbles that are meant to convey that we all know what kind of kids we are talking about although it is no longer safe to label them. 
The unrealistic part of the child-centered faith is the belief that each child's natural curiosity should be sufficient to sustain knowledge-seeking six or more hours a day for 12 or more years. Those of us who are trying to change classroom culture are not banking on that. Rather, the expectation is that if the production of usable knowledge gets established as the classroom's collective task, then ordinary motives of conformity and citizenship will suffice to keep students engaged when curiosity flags. There may be situations where establishing the classroom as a knowledge production workshop proves impossible, but it is certainly a more attainable objective than keeping the curiosity of 30 individual students constantly aroused.

\section{Knowledge Construction in the Classroom}

The idea of schools as workshops for the construction of knowledge wins ready assent from educators. The difficulty is in getting them to see that this is anything different from students planning space missions: It is all "project-based learning" or playing at being scientists. In discussing adult organizations earlier, it was easy to distinguish learning from knowledge building. Everyone learns, and progressive organizations do much to promote learning, but learning is not what people are employed for. Creating or adding value to knowledge, by constrast, is the purpose of an increasing number of jobs. Learning is the reason we send children to school, however, and knowledge building is only going to be valued insofar as students learn from doing it. But that does not make the distinction between learning and knowledge building any the less important. Students currently engage in all kinds of schoolwork, from doing sheets of arithmetic exercises to producing elaborate multimedia presentations, most of which is far removed from any kind of work that goes on in a knowledge society. A simple way to put my proposal, therefore, is as follows: Since students need to do some kind of work in order to learn, why not let that work be the construction of knowledge? The reason we need a distinction between learning and knowledge building is in order for a statement like that to make sense.

One major prejudice must be overcome if knowledge building, as real productive work similar to what goes on in industrial laboratories and university research centers, is to find a foothold in educational policy. This is the prejudice that bestows credit only on the first person to come forth with an idea. Although this may be a perfectly reasonable principle in patent law, when generalized it virtually denies the possibility of children's being real creators of knowledge; for 
rarely if ever will a child produce knowledge that is new to the world. But originality is always relative to context. If it should turn out that there are intelligent beings on another planet and that everything scientists on earth have discovered is already old hat to them, would that mean that Newton and Darwin were not scientists after all?

Furthermore, an original theory or explanation is only one kind of knowledge product, albeit an exceptionally important one. Other worthwhile products of knowledge building are interpretations of theories, criticisms, translations of them into simpler terms, analyses of their implications or applications in some context of interest, descriptions of phenomema which the theory does or does not explain, experimental demonstrations, simulations, and historical accounts. Many adults pursue respectable careers producing knowledge of these kinds, often demonstrating creativity and depth of insight in the process. There is no reason to deny students credit when they do likewise.

A student in a CSILE class enters a note asking what keeps gravity from leaving the earth. Later another student reports that she has read that gravity is a force between things and therefore not something contained within things. Several students seize on this as making sense of the idea they have heard that gravity is everywhere. As we adults read these notes we conclude that a genuine advance in knowledge has occurred, helped along as much by the first student's naive question as by the second student's important finding. We do not know how much has been learned - that is, how much individual students in the class will carry away from this episode. Undoubtedly it will vary. What we do know is that knowledge has been produced, not of news-making or prize-winning calibre, but as important to the intellectual world that the students live in as the discoveries of a leading-edge university research team are to the intellectual world they live in. That is really all we need to allow in order to accept knowledge building by students as genuine productive work rather than merely a learning activity.

Students in any kind of classroom ought to be able to respond informatively to the question, "What have you learned?" As many parents have found, this is often a difficult question for young people. But in the kind of knowledge building classroom I am advocating, students should also be able to answer an even more challenging question: "What advances in knowledge has your class made?" Answering such a question requires not only an awareness of one's own mental state but also an awareness of that abstraction known as 'the state of 
knowledge' in a community. The answer would of course overlap in content with answers to "What have you learned?" but it would take quite a different form. It might go like this: "Well, we've been working on systems of the body and we started out with one group studying the eye and another group studying the brain. But pretty soon we realized that to understand how we see we had to work on how the brain and the eye are connected. We have a pretty good idea now of how information gets from objects to the retina and from the retina to the brain, but we don't understand what happens after that-like, how you know what you're looking at. Some kids don't think that's a problem, but I do.... We've also been working on the Aztecs and the Incas and those other groups. We've collected lots of information, but we're just starting to put it together to understand what their civilizations were like. It's hard, you know, because they didn't think about things the way we do...."

The preceding example combines remarks made by various students when asked to tell about their class's work. I suggest it is very similar to what one might get on dropping in on a university research group and asking how their work was going. The knowledge that the students have constructed is of course of a different order, but their unsolved problems are indeed unsolved in the world at large. They can legitimately claim membership in the communities of people who are working on such problems. They are, in short, doing real knowledge building, not playing pretend.

Over the span of the school years, the job of students in the knowledge workshop is to construct an understanding of the whole world. That was the job Aristotle undertook, only today's students may go at it with more help and with improved tools and resources. The achievement of such a unified and comprehensive understanding has traditionally been the highest aim of liberal education. However, in the past it has been seen as largely a matter of gaining possession of an existing understanding of the known world, such as Aristotle's or those of the medieval Summae or later the enlightenment project of Diderot's Encyclopedie. There were, of course, students who went beyond these fixed understandings to construct knowledge of their own, but in doing so they went well beyond the expectations of the curriculum and perhaps even beyond its allowable limits. The proposal to make knowledge building the principal activity in schooling would mean enlarging liberal education so as to encompass both the grasping of what others have already understood and the sustained, collective effort to extend the boundaries of what is known. 


\section{Enculturation into World 3}

In the preceding section I suggested that knowledge building could be thought of as simply another kind of schoolwork, a kind especially appropriate to students in a knowledge society. But there is much more to it than that. Multiculturalists, Marxist critics, and advocates of liberal education are alike in regarding schooling as a form of enculturation. To answer the question "What should it mean to be an educated person in the 21st century?"we have to consider what kind of culture is foreseen and how schooling should relate to it. There is much more to this issue than I can begin to address. The uncertainties of prediction and the alarming nature of many trends in contemporary culture are daunting.

One social prediction seems much less risky than others, however, and that is the expectation of a continuing rise in the importance of knowledge and knowledge work. The only way this prediction could prove wrong would be if knowledge and technology stopped advancing, and barring worldwide suppression that could not occur. We do not know what the social consequences will be for employment, equity, quality of life, and so on-no matter how confidently pundits may extrapolate current trends. What we can say is that knowledge will be an increasingly salient part of the environment. You will not know your way around in tomorrow's world unless you know your way around knowledge.

A statement like the preceding can, however, mean next to nothing in a discussion of educational policy. To many people these days it will mean knowing your way around on the Internet, knowing how to do searches for Worldwide Web documents. The Web does, in fact, nicely epitomize a world overrun with knowledge; and so I am amazed to keep encountering writers on the Web proclaiming the centrality of information search skills as an educational objective for the knowledge age. The skills needed to do Web searches can be learned in a few hours (less, if you know a bit of Boolean algebra). But years of subject-matter learning must come to the fore if you are to avoid retrieving thousands of documents none of which contains the information you were hoping to find. Knowing your way around the Worldwide Web really means being on familiar terms with world knowledge in its manifold aspects. The more you know the greater your chance of learning something new. That is the real excitement of the new knowledge resources, yet it seems scarcely to be appreciated at all by the information media enthusiasts presuming to lead 
education into the knowledge age. If it were appreciated, it would go some way toward re-establishing the importance of liberal education.

The trouble, I believe, lies in a folk psychology which conceives of the mind as a storehouse of items of information, along with a set of mental abilities and skills for working with those items. ${ }^{5}$ With this conception, it is very difficult to think of knowledge as the principal basis for finding or acquiring new knowledge, just as it is difficult to think of knowledge production as distinct from learning. We need a broader conception of knowledge. We must be able to treat it as a part of the world-along with computers, CD players, backpacks, and street people-that students become enculturated into. Without that, I fear, schooling will remain lodged in an earlier and more primitive age, no matter how many computers line the walls, and will little prepare students for the world that exists on the other side of the modem.

Working out a vision for education in a knowledge society minimally requires taking account of knowledge in two quite distinct senses: first, knowledge as something that people acquire and that becomes a part of them; second, knowledge as something that they work with and that in some sense takes on a life of its own. The knowledge building classroom, as I have been characterizing it, embodies this dual conception of knowledge. It thus presents a miniature of the knowledge society into which students are to become enculturated.

Common sense of course recognizes this dual character of knowledge. When we talk about a child 'knowing (or not knowing) the Pythagorean theorem' we simultaneously refer to knowledge as an attribute of the child's mental state and to the Pythagorean theorem as a piece of knowledge in its own right-as something created by a mathematician in ancient times and surviving to this day as a worthwhile thing-to-be-known. But in order to carry on a serious discussion about knowledge in education, we need distinguishing labels. Karl Popper has provided some, which can be quite useful so long as we are careful not to encumber them with excess meaning. The labels come from his metaphor of three worlds. World 1, the physical world, need not concern us at this point.

${ }_{5}$ A still influential work in curriculum planning, Bloom's Taxonomy of Educational Objectives, makes this view of knowledge explicit:

[T]hink of knowledge as something filed or stored in the mind. The task for the individual in each knowledge test situation is to find the appropriate signals and cues in the problem which will most effectively bring out whatever knowledge is filed or stored. (Bloom, 1956, p. 29) 
The important distinction is between Worlds 2 and 3 . World 2 is the subjective world, comprising the knowledge in people's heads. (Without doing violence to Popper's concept, we can expand World 2 to include situated knowledge as well-knowledge that is implicit in the practices of communities and not assignable to individual minds.) World 3 is, roughly speaking, the world of ideas. It consists of immaterial knowledge objects that can be discussed, modified, replaced, and so on. ${ }^{6}$ The Pythagorean theorem is an object in World 3. The child's knowledge of the Pythagorean theorem is part of the child's World 2. The distinction thus coincides with the distinction I have been making between knowledge building and learning. Knowledge building is work carried out to produce changes in World 3. Learning consists of changes in World 2.

From an educational standpoint, what is especially attractive about the World 3 idea is that it encompasses both the traditional idea of a fund of accumulated knowledge that is passed on to the young and the more dynamic idea of knowledge advancing through people's creative efforts. We may think of World 3 as a workspace in which there are knowledge objects in various stages of development. Some are finished to the extent that no one bothers to tinker with them anymore. Some, like phlogiston theory, are of no current value and are preserved for historical interest only. Others are under current development and are the subjects of research, criticism, controversy, repair operations, and novel conjecture. The Pythagorean theorem is one of the finished objects of World 3. But when students produce explanations of the theorem or intuitive proofs or examples of application, these are World 3 objects as well and the activity that produces them is work in World 3, just as was the work of Pythagoras. This conception of World 3 as a realm of activity stretches Popper's concept, but not very much. He said at one point (1972, p. 156), "I suggest that one day we will have to revolutionize psychology by looking at the human mind as an organ for interacting with the objects of the third world; for understanding them, contributing to them, participating in them; and for bringing them to bear on the first world." This seems an apt description of mind in the knowledge age. Translating it into an educational prescription leads naturally to thinking of World 3 as a workspace and of education as providing entrée to it.

\footnotetext{
${ }^{6}$ Note that this is different from Plato's world of ideas, which pre-exist human understanding and are enternal. World 3 is wholly a human construction and is undergoing continual renovation.
} 
Accordingly, we may define the role of schools in the knowledge age as follows: It is to enculturate students into World 3. Enculturation into World 3 entails much more than mastering a body of established knowledge. Indeed, it leaves open such questions as what constitutes established knowledge and what needs to be mastered and in what ways. It implies, rather, that those perennial curriculum issues should be considered within the context of students' active participation in the world where such issues matter. Enculturation into any world means becoming familiar with what is there, learning how to act, becoming involved in what is going on, and generally coming to feel at home in it. At a deeper level, enculturation implies that artifacts and activities will come to have a meaning for the newcomer that is consistent with the meaning they have for others in that world. This does not mean that one becomes the same as everyone else, but it does mean that the world is no longer exotic, bewildering, or forbidding.

My favorite line expressing enculturation into World 3 appeared in a computer-based dialogue among elementary school students inquiring into problems of genetics: "Mendel worked on Karen's problem." Captured in these five words is the sense of a shared knowledge building enterprise, continuity with the past, and the conception of a World 3 object (in this case, a formulated problem) that persists over time and space and that various people may work on in different ways. In short, a whole epistemology is represented here, an epistemology sophisticated enough for the knowledge age and something far beyond what educators speak of as 'cooperative learning,' 'problem-based learning,' 'constructivist learning,' or (groan) 'learner-centered education.' It is knowledge-centered education; and Mendel gets into the picture, not as a dead white male with the authority of the scientific establishment behind him but as someone with a contribution to make to a current knowledge problem.

For Popper, as a philosopher of science, World 3 consisted primarily of discussible propositions or declarative knowledge-theories, conjectures, problem formulations, historical accounts, interpretations, proofs, criticisms, and the like. However, he saw these as cultural objects existing in a larger world that includes other cultural objects such as poems, sonatas, folktales, food recipes, rituals, and monuments. Liberal education is enculturation into this larger world of cultural objects. World 3 is and always has been an important part of the world for liberal education. What I am proposing is that World 3-especially in 
its constructive, creative aspect-needs to become a larger part, if liberal education is to rise to the challenges of the knowledge age.

The world of cultural objects is quite different for a liberally educated Indonesian, for instance, from what it is for a liberally educated Italian. To be sure, both would probably score better on a test of cultural literacy than would the average American student for whom it was designed; but in the art, literature, music, and history with which they are intimately familiar, there will be profound differences. These differences are valuable; cultures are kept alive by people who cherish and live on intimate terms with the objects of their cultures, and this is much of what gives richness to life. Nothing I say should be thought to deny these time-honored values. But it is important to recognize that things are different with the objects of World 3. Multiculturalists to the contrary, there are not culture-specific sciences, mathematics, literary or historical theories. ${ }^{7}$ There are cultural differences, just as there are individual differences, in how people think about these things; but they are not differences that preclude constructive criticism and collaborative knowledge building. Or if they are, then something is wrong that education needs to set right.

The boundaries of World 3 are approximately the boundaries of what can be profitably argued about in general terms. ${ }^{8}$ Liberal education, I am suggesting, has the dual task of expanding those boundaries and of equipping students to engage in the argument. Not that arguing is all one does with World 3 objects; there is finding implications and applications, explaining, comparing, revising, and so on. But if a proposition is not arguable it is generally not amenable to these other operations either, and if people do not understand a World 3 object well enough to argue constructively about it they are probably not competent to do much else with it.

Liberal education today is embroiled in serious controversy about what cultural objects, representing whose culture, are to figure in the curriculum. This is an important controversy, accentuated by the increasing cultural divisions to be found within modern societies. But the largest cultural divide, cutting across the

\footnotetext{
${ }^{7}$ Part of the multiculturalist-postmodernist argument, however, is to reject a distinction between science and myth (cf. Rorty, 1991). But myths do not put forth arguable propositions, and no one would even think of disputing, much less believing some other culture's creation myths, for instance. Science and scholarship, in contrast, do put forth propositions that are open to challenge by anyone anywhere and it is thus that World 3 transcends cultural boundaries. ${ }^{8}$ The qualifier, "in general terms," is needed because most of what people argue about, of course, in everyday life are particular cases, and these are not World 3 objects.
} 
whole world with great consequence, is that which separates people who are at home in World 3 from those who are not. Any decision about enculturation that excludes students from enculturation into a cosmopolitan World 3 is a serious denial of children's rights to education. Exclusion from World 3 could come in the form of an educational program so intent on preserving indigenous culture or ethnic pride that it relegates World 3 to the status of a foreign culture. This is what is happening when educators start referring to 'Eurocentric science,' for instance. Or exclusion could take the form of an educational program so childcentered or so intent on learning objectives that there is no participation in any larger intellectual world.

Much of what is going on in education seems to be exclusionary in one or more of these ways. Worse than that, it seems that the education system itself is on the wrong side of the cultural divide, ill-disposed to treat knowledge as a focus of productive work. Better models of schooling are available, models that are compatible with the needs of a knowledge-based economy, with the best of cognitive learning research, and with enduring values of liberal education. But those models cannot simply be taken up as variations on project-based learning or whatever new method comes to the fore. In order to move to the other side of the divide, in order to find their place in a knowledge society, schools must undergo a much more radical transformation. Only by becoming knowledge building organizations themselves, I believe, can schools hope to provide students with a way into the life of a knowledge society.

\section{References}

Anderson, R. C., \& Pearson, P. D. (1984). A schema-theoretic view of basic processes in reading comprehension. In P. D. Pearson (Ed.), Handbook of reading research (pp. 255-292). New York: Longman.

Bereiter, C., \& Scardamalia, M. (1996). Rethinking learning. In D. O. \&. N. Torrance (Eds.), Handbook of education and human development: New models of learning, teaching and schooling (pp. 485-513). Cambridge, MA: Basil Blackwell.

Bloom, B. S. (Ed.). (1956). Taxonomy of educational objectives: Handbook 1. Cognitive domain. New York: David McKay Company, Inc. 
Brown, A. L. (1978). Knowing when, where, and how to remember: A problem of metacognition. In R. Glaser (Eds.), Advances in instructional psychology (pp. 77-165). Hillsdale, NJ: Lawrence Erlbaum Associates.

Brown, A. L., \& Campione, J. C. (1990). Communities of learning and thinking, or A context by any other name. Contributions to Human Development, 21, 108-126.

Brown, A. L., \& Campione, J. C. (1994). Guided discovery in a community of learners. In K. McGilley (Eds.), Classroom lessons: Integrating cognitive theory and classroom practice (pp. 229-270). Cambridge, MA: MIT Press.

Chi, M. T. H., Glaser, R., \& Farr, M. (Ed.). (1988). The nature of expertise. Hillsdale, NJ: Erlbaum.

Doyle, W. (1986). Classroom organization and management. In M. C. Wittrock (Eds.), Handbook of research on teaching (pp. 392-431). New York: Macmillan.

Drucker, P. (1993). Post-capitalist society. New York: HarperBusiness.

Gardner, H. (1983). Frames of mind: The theory of multiple intelligences. New York: Basic Books.

Palincsar, A. S., \& Brown, A. L. (1984). Reciprocal teaching of comprehensionfostering and comprehension-monitoring activities. Cognition and Instruction, 1, 117-175.

Popper, K. R. (1972). Objective knowledge: An evolutionary approach. Oxford: Clarendon Press.

Popper, K. R., \& Eccles, J. C. (1977). The self and its brain. Berlin: Springer-Verlag. Rorty, R. (1991). Objectivity, relativism, and truth: Philosophical papers, Vol. 1. Cambridge: Cambridge University Press.

Scardamalia, M., \& Bereiter, C. (1994). Computer support for knowledgebuilding communities. Journal of the Learning Sciences., 3(3), 265-283.

Scardamalia, M., \& Bereiter, C. (in press). Schools as knowledge building organizations. In D. Keating (Eds.), $\underline{\mathrm{xx}}$

Scardamalia, M., Bereiter, C., \& Lamon, M. (1994). The CSILE project: Trying to bring the classroom into World 3. In K. McGilley (Eds.), Classroom lessons: Integrating cognitive theory and classroom practice (pp. 201-228). Cambridge, MA: MIT Press.

Scardamalia, M., Bereiter, C., \& Lamon, M. (1994). The CSILE project: Trying to bring the classroom into World 3. In K. McGilley (Eds.), Classroom lessons: 
Integrating cognitive theory and classroom practice (pp. 201-228). Cambridge, MA: MIT Press.

Wandersee, J., Mintzes, J., \& Novak, J. (1994). Research on alternative conceptions in science. In D. Gabel (Eds.), Handbook of research on science teaching and learning (pp. 177-210). New York: Macmillan.

Wenger, E. (1995). Communities of practice. New York: Cambridge University Press.

White, G., \& Korner, G. (1995). Just in time learning on the Internet. Stanford University, Center for the Study of Learning and Instruction. (WWW page, http:/ / www-csli.stanford.edu/csli / projects/interface9495-jitl.html.)

Yarnall, L., \& Kafai, Y. (April, 1996). Issues in project-based science activities: Children's constructions of ocean software games. Paper presented at the annual meeting of the American Educational Research Association, New York. (WWW page, http:/ / www.gse.ucla.edu/kafai / Paper_Kafai\%2FYarnall.html). 